\title{
KINETICS AND MECHANISM OF THE NICKEL ELECTRODE-I. ACID SOLUTIONS CONTAINING A HIGH CONCENTRATION OF CHLORIDE AND NICKEL IONS*
}

\author{
J. R. Vilche and A. J. Arvía \\ Instituto de Investigaciones Fisicoquimicas Teóricas y Aplicadas, División Electroquimica, Facultad \\ de Ciencias Exactas, Universidad Nacional de La Plata, La Plata, Argentina

\begin{abstract}
The kinetics of the $\mathrm{Ni}$ electrode in acid solutions with a high chloride ion concentration has been investigated in the range of $25-75^{\circ} \mathrm{C}$. Dissolution occurs uniformly only at low anodic potentials. When the latter exceeds a critical value, $E_{\text {crit }}$, net localized metal corrosion takes place. The $E / \ln i_{a}$ plot at $E<E_{\text {crit }}$ corresponds to a curve approaching two limiting slopes, namely, $2 R T / 3 F$ at $\left(E-E_{\text {reet }}\right) \rightarrow 0$, and $2 R T / F$ at $E \rightarrow E_{\text {crit }}$. The cathodic Tafel slope is $2 R T / F$. These results, including their $\mathrm{pH}$ dependence, are explained with a reaction mechanism involving the participation of adsorbed hydroxo-species.
\end{abstract}

\section{INTRODUCTION}

THE ELECTROCHEMICAL behaviour of $\mathrm{Ni}$ in aqueous and non-aqueous solutions and in ionic melts is complex, depending among other things, on the ionic composition of the medium, crystal orientation, thermal treatment of the metal and on the type of perturbation applied to the metal/solution interface. Thus, the corrosion and passivity of $\mathrm{Ni}$ in strong acid electrolytes depend markedly on the type of anion present in solution. This is quite evident, for instance, by comparing $\mathrm{Ni}$ electrode behaviour in concentrated $\mathrm{HCl}$ and in concentrated $\mathrm{H}_{2} \mathrm{SO}_{4}$ solutions. A review on the subject has been published. ${ }^{1}$

The work presented below refers to the electrochemistry of $\mathrm{Ni}$ in concentrated solutions containing $\mathrm{Cl}^{-}$and $\mathrm{Ni}^{2+}$ ions, a system which, although frequently employed in metal electroplating, is not still completely understood from the mechanistic viewpoint. Thus, most of the reaction mechanisms proposed for $\mathrm{Ni}$ electrodissolution are closely related to those postulated for the active dissolution of $\mathrm{Fe}$ and $\mathrm{Co}, 1,2$ which involve hydroxo-metal intermediate adsorbed at the electrode formed both during the anodic and the cathodic reactions. In contrast, in a recent study of $\mathrm{Ni}$ in acid $\mathrm{NiCl}_{2}$ solutions, ${ }^{3}$ it was concluded that no hydroxo-complexes of metal ions participate either in the anodic or in the cathodic processes of $\mathrm{Ni}$ electrodes. This interpretation, however, is derived from data covering a relatively narrow potential range and probably involving some appreciable metal surface change during the measurement of the stationary $E / I$ curves. Anodic polarization curves covering a wide range of anodic potential have also been obtained and the single Tafel slope drawn at high potentials seems to be somewhat arbitrary. ${ }^{4}$

This paper describes the occurrence of net changes of the metal surface area as the anodic potential exceeds a certain critical value. There is, therefore, a rather limited potential range where the $E / I$ curves can be referred to a constant electrode area. The active metal dissolution occurring there is interpreted with respect to a single complex

*Manuscript received 24 January 1975. 
reaction mechanism involving different rate-determining steps according to the anodic potential range considered.

\section{EXPERIMENTAL}

The Pyrex glass electrolysis cell of ca. $350 \mathrm{~cm}^{3}$ was a conventional one and consisted of three double wall compartments to lodge respectively the working electrode, the counter electrode and the reference electrode. The latter was shielded with a usual Luggin-Haber capillary tip arrangement.

The working electrodes were made from Specpure $\mathrm{Ni}$ wire (Johnson-Matthey) with the following impurities in ppm: $\mathrm{Fe}, 5 ; \mathrm{Cu}, 2 ; \mathrm{Si}, 2 ; \mathrm{Mg}, 1 ;$ and $\mathrm{Al}, \mathrm{Ca}$ and $\mathrm{Ag}$ less than 1 . The wires were previously annealed during $16 \mathrm{~h}$ at $900^{\circ} \mathrm{C}$ in an argon atmosphere. The $\mathrm{Ni}$ wires were inserted into a Tefion rod to be used as electrodes $\left(0.5 \mathrm{~cm}^{2}\right)$.

The counter electrode was a large area $P t$ sheet previously cleaned with the usual procedures. A saturated calomel electrode was also employed $\left(E_{\mathrm{NHE}}=0.241 \mathrm{~V}\right.$ at $\left.25^{\circ} \mathrm{C}\right)$ but potentials were referred to the standard hydrogen electrode scale.

Solutions containing $1.0 \mathrm{~N} \mathrm{NiCl}_{2}+x \mathrm{~N} \mathrm{HCl}+y \mathrm{~N} \mathrm{NaCl}(x+y=0.05)$ were employed. They were prepared from analytical reagents and triple distilled water. During the experiments the solutions were kept under either nitrogen or hydrogen, depending on the purpose.

Experiments were made at 25,50 and $75 \pm 0.05^{\circ} \mathrm{C}$. The following techniques were applied: (i) stationary potentiostatic methods, (ii) potentiodynamic linear single sweep and (iii) triangular cyclic voltammetry. The corresponding circuitry was the same already described elsewhere. ${ }^{5}$

\section{The rest potentials}

\section{RESULTS}

When a $\mathrm{Ni}$ electrode is immersed in $\mathrm{NiCl}_{2}+\mathrm{NaCl}$ solutions with different $\mathrm{HCl}$ concentrations, its potential changes with time (Fig. 1). Initially they turn abruptly more cathodic, attaining a minimum value at $c a .5 \mathrm{~min}$. Then, it decreases approaching a constant rest potential, $E_{\text {rest }}$, after about $2 \mathrm{~h}$. The $E_{\text {rest }}$ value decreases with temperature, being more reproducible as the temperature increases.

At low $\mathrm{HCl}$ concentrations $\left(<10^{-2} \mathrm{M}\right)$ the initial immersion potential, $\left(E_{\eta}\right)_{0}$, increases linearly with logarithm $C_{\mathrm{HCl}}$, the slope of the straightline approaching the $2.303(R T / 2 F)$ ratio (Fig. 2). Values of $E_{\text {rest }}$ at $55^{\circ} \mathrm{C}$ can be correlated with previously

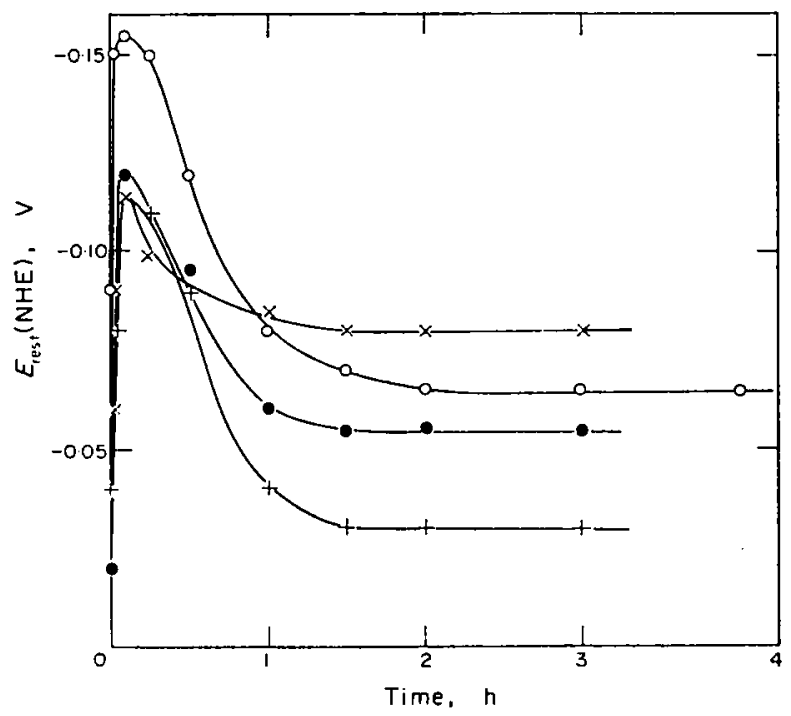

FiG. 1. Time dependence of the corrosion potential; $1 \mathrm{~N} \mathrm{NiCl}, 0.05 \mathrm{~N} \mathrm{NaCl}+$ $x \mathrm{~N} \mathrm{HCl}, 25^{\circ} \mathrm{C}$. (O) $x=10^{-6} ;(\times) x=10^{-5} ;(+) x=10^{-4} ;(\bullet) x=10^{-3}$. 


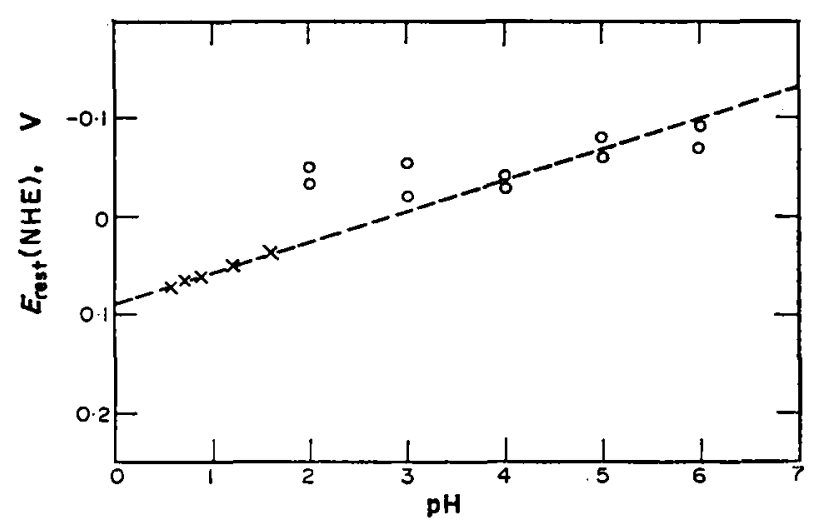

Fig. 2. $\mathrm{pH}$ dependence of the corrosion potential; $1 \mathrm{~N} \mathrm{NiCl}, 0.05 \mathrm{~N} \mathrm{HCl}, 25^{\circ} \mathrm{C}$. $(0)$ present work; $(x)$ from Ref. 3.

reported results where electrolytic solutions of the same composition, ${ }^{3,4}$ (Fig. 2) have been employed.

\section{Potentiostatic E/I curves}

Typical potentiostatic anodic $E / \log i$ plots are shown in Figs. 3 and 4 . The latter includes also cathodic $E / \log i$ plots. In the potential range from $E_{\text {rest }}$ to $0.340 \mathrm{~V}$ (at $25^{\circ} \mathrm{C}$ ) each current reading was made $3 \mathrm{~min}$ after the potential step was applied,

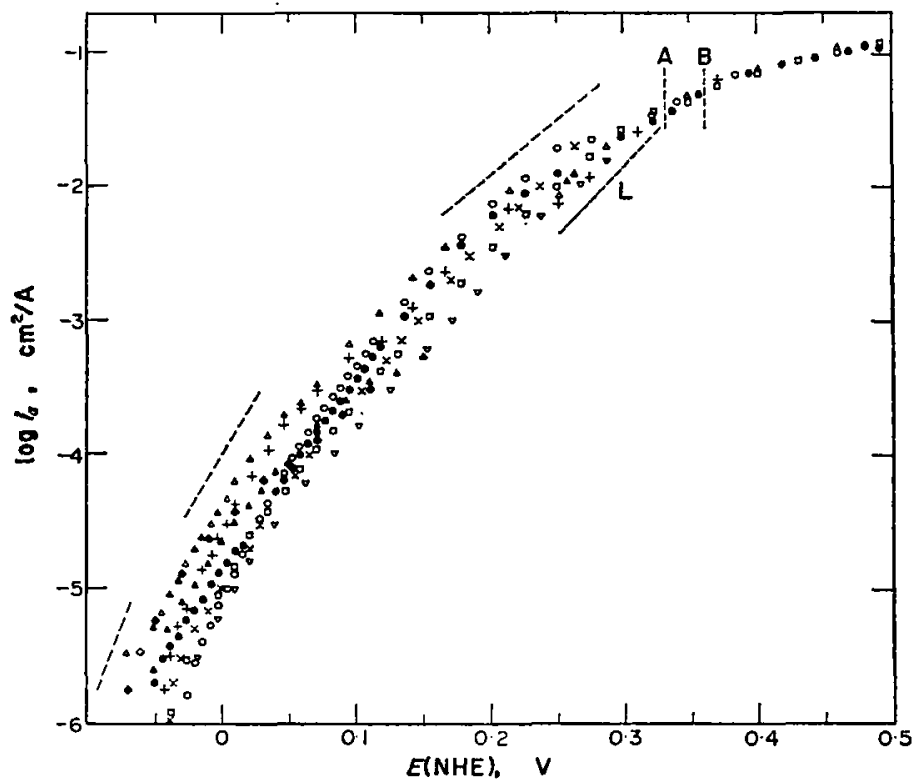

FIG. 3. Semi-logarithmic plots of anodic polarization curves; $1 \mathrm{~N} \mathrm{NiCl}, 0.05 \mathrm{~N} \mathrm{HCl}$; $25^{\circ} \mathrm{C}$. Each symbol corresponds to a particular run. Lines A and B define the potential range beyond which the anodic current steadily increases with time. Dashed lines correspond to the theoretical anodic Tafel slopes discussed in the text. The one indicated with $L$ is related to the Tafel slope and potential region given in Ref. 4. 


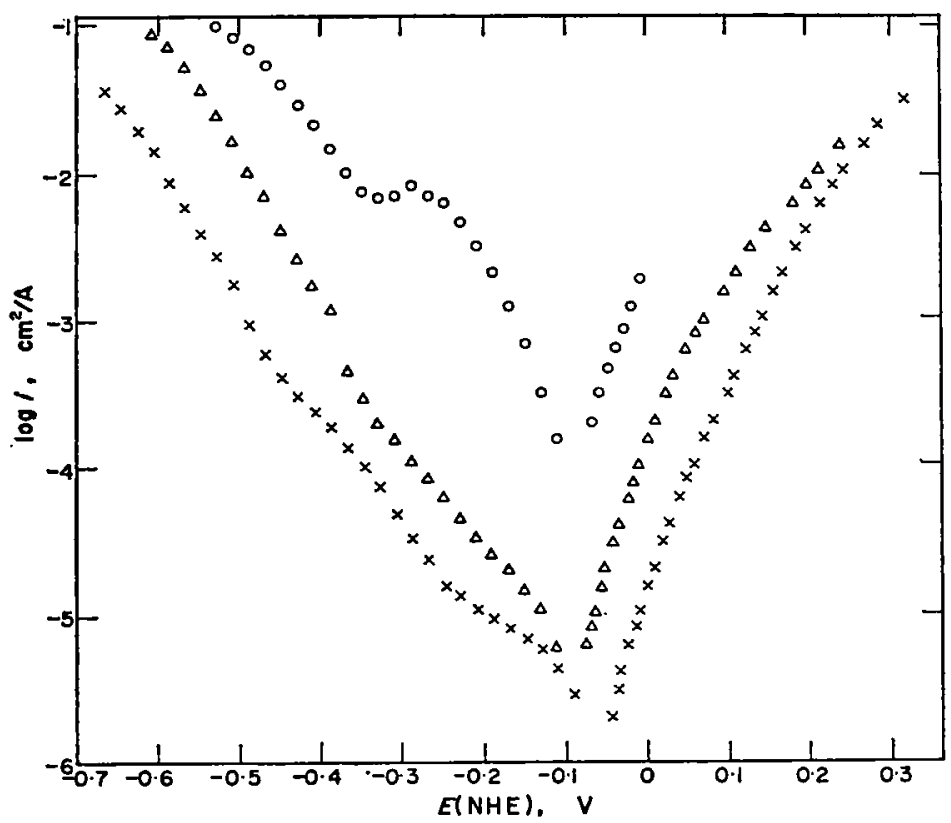

FIG. 4. Semi-logarithmic plots of anodic and cathodic polarization curves; $1 \mathrm{~N} \mathrm{NiCl}_{2}$, $0.05 \mathrm{~N} \mathrm{HCl} ;(\times) 25^{\circ} \mathrm{C} ;(\Delta) 50^{\circ} \mathrm{C} ;(0) 75^{\circ} \mathrm{C}$.

assuring a constant current for at least one minute. Beyond $0.340 \mathrm{~V}$ (at $25^{\circ} \mathrm{C}$ ) no stable current reading could be made. Those plotted in Fig. 3 were made 1 min after the potential had been applied. The trend of the current, however, was to increase continuously. In the investigated potential region $\mathrm{Ni}$ dissolution occurs as $\mathrm{Ni}$ (II) ion. The anodic $E / \log i$ plot corresponds to a smooth curve whose initial slope is very close to $2 \cdot 303(2 R T / 3 F) \mathrm{V} /$ decade and the slope in the high potential region becomes close to $2 \cdot 303(2 R T / F) \mathrm{V} /$ decade (Fig. 4).

The cathodic $E / \log i$ plot is complex since it involves the simultaneous discharge of $\mathrm{H}^{+}$and $\mathrm{Ni}^{2+}$ ions. As it is already known, the ratio of the current efficiencies of these processes depends both on temperature and concentration of the reacting species. Thus, as temperature increases the efficiency for the $\mathrm{H}_{2}$ evolution reaction apparently increases more markedly than that of the nickel electrodeposition. At low temperatures each cathodic process individually considered is related to a Tafel slope close to $2.303(2 R T / F)$. But as the activation energies of those reactions are different both processes tend to approach a relatively large rate already at low cathodic potentials when the temperature increases. This causes a limiting cathodic current related to the hydrogen evolution at $75^{\circ} \mathrm{C}$.

The intersection of the anodic and cathodic $E / \log i$ plots yield an extrapolated value of the corrosion potential, $\left(E_{\text {corr }}\right)$, which within the experimental errors, coincides with $E_{\text {rest }}$. The apparent corrosion current density, $i_{\text {corr }}$, is also immediately obtained. Similarly, the extrapolation to $\left(E_{\mathrm{rev}}^{\mathrm{Ni}}\right)$ of the $E / \log i$ lines related to the $\mathrm{Ni}$ electrode reactions, yields values of the apparent exchange current density, $i_{0, a p p}$. Kinetic parameters at different temperatures are assembled in Table 1. 
TABle 1. KinetiC parameters derived from the TAFel Plots $1 \mathrm{~N} \mathrm{NiCl}+0.05 \mathrm{~N} \mathrm{HCl}$

\begin{tabular}{ccc}
\hline$T\left({ }^{\circ} \mathrm{C}\right)$ & $\log \left(i_{0, \mathrm{app}}\right)_{\mathrm{M} 1} \times\left(\mathrm{cm}^{2} / \mathrm{A}\right)$ & $\log \left(i_{\mathrm{corr}}\right) \times\left(\mathrm{cm}^{2} / \mathrm{A}\right)$ \\
25 & -8.8 & -6.1 \\
50 & -7.4 & -5.3 \\
75 & -6.0 & -4.1 \\
\hline
\end{tabular}

\section{Potentiodynamic E/I curves}

The potentiodynamic $E / I$ characteristics obtained with single triangular potential sweeps depend on $\underline{v}$, the rate of potential scanning, on $\Delta E$, the amplitude of the scanned potential, and on the temperature.

At $25^{\circ} \mathrm{C}$, (Fig. 5), when $E \leq E_{\text {crit }}=0.34 \pm 0.02 \mathrm{~V}$, the first $E / I$ trace run from $E_{\text {rest }}$ towards anodic potentials and the reverse one are practically coincident. But when $E>0.34 \mathrm{~V}$, a definite increase of the dissolution rate is observed which is more notorious as $E$ further increases. Finally, when $E>0.38 \mathrm{~V}$, the current increases abruptly (Fig. 6), exhibiting a clear activation-type-loop, during the returning potential sweep (Fig. 7). The anodic current peak resulting during the reverse scan shows a significant symmetry. Figure 7 also shows the influence of $E$ on the anode activation. Therefore, during the potentiostatic runs, at $25^{\circ} \mathrm{C}$, the value $E=0.34 \mathrm{~V}$ establishes a potential limit below which steady values of current are attained. The $E / I$ characteristics just mentioned are always observed within the whole temperature range investigated, although the activation loop occurs at potentials lower than those already reported at $25^{\circ} \mathrm{C}$.

\section{Repetitive triangular potential scan}

The activation effect is also well noticed by repetitive potential cycling of the working electrode within the appropriate potential value (Fig. 8). The returning half-cycle, at a potential ca. $0.2 \mathrm{~V}$, exhibits a limiting current, which increases in the successive potential cycles. Its value in the returning half-cycle is the same observed during the second half-cycle when the potential changes upwardly; that corresponding to the returning second half-cycle coincides with the value recorded at the third cycle

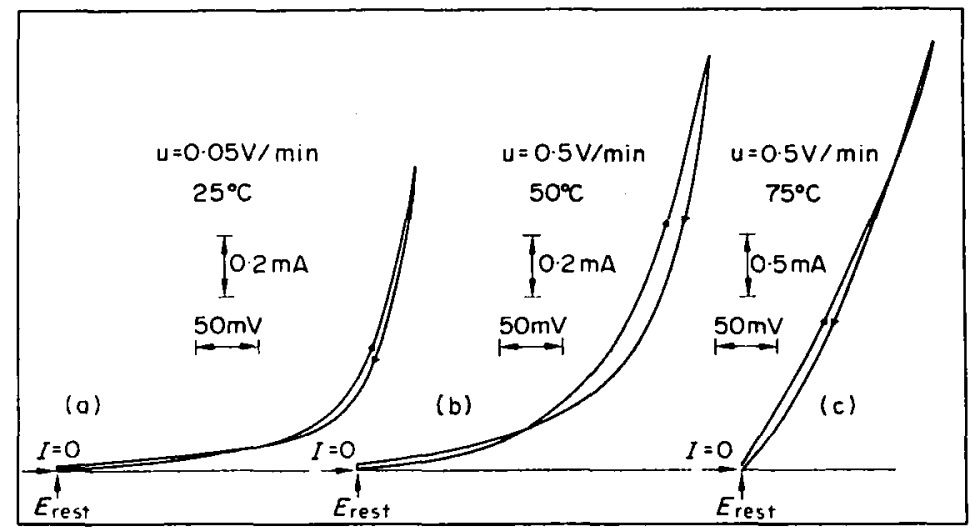

FIG. 5. Potentiodynamic anodic $E / I$ curves covering the active dissolution region, run at different potential sweep rates and temperatures; $1 \mathrm{~N} \mathrm{NiCl}_{2}, 0.05 \mathrm{~N} \mathrm{HCl} ;$ (a) $E_{\text {rest }}=$ $-0.075 \mathrm{~V}$; (b) $E_{\text {reat }}=-0.100 \mathrm{~V}$; (c) $E_{\text {rest }}=-0.120 \mathrm{~V}$. 


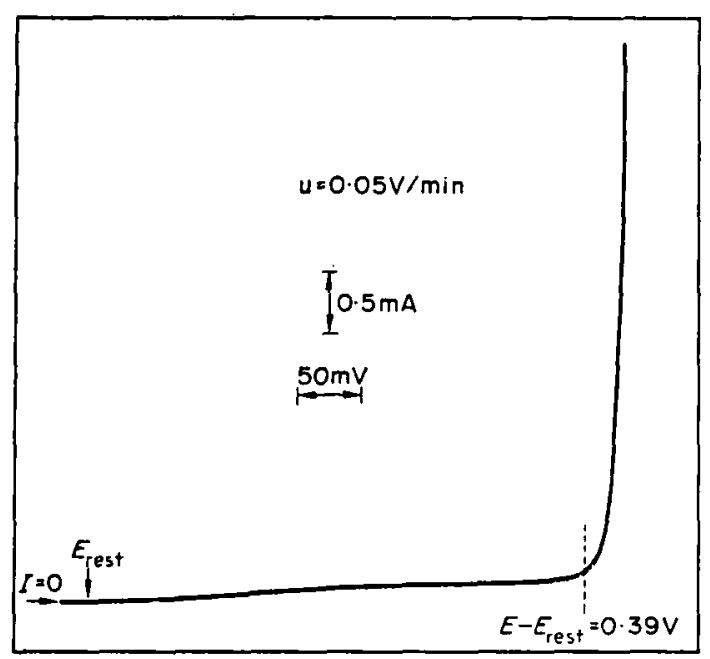

FIG. 6. Potentiodynamic anodic $E / I$ curve covering the critical potential region; $1 \mathrm{~N} \mathrm{NiCl}, 0.05 \mathrm{~N} \mathrm{HCl} ; 25^{\circ} \mathrm{C}$.

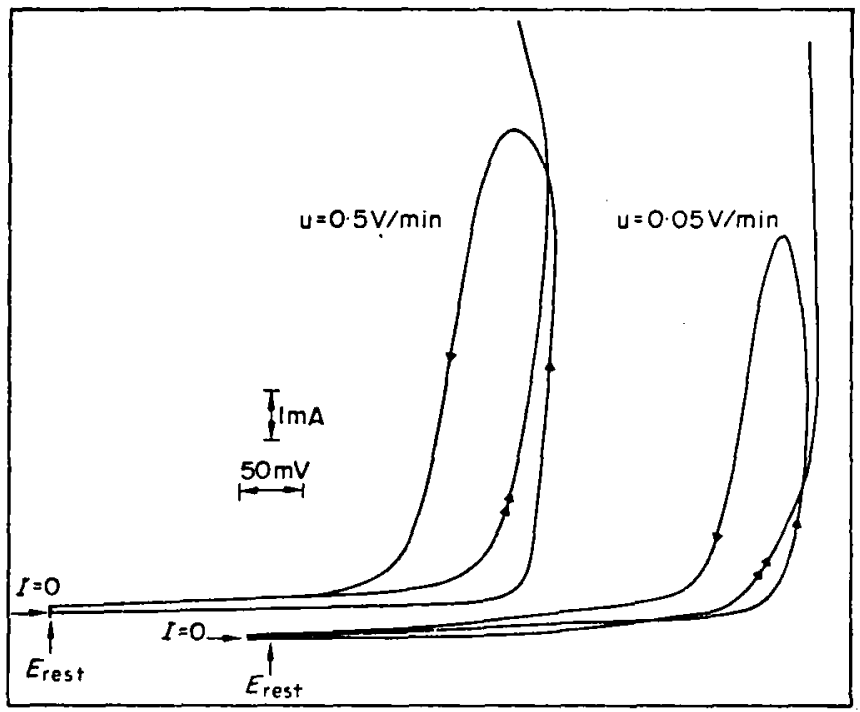

Fig. 7. Anodic triangular potential sweeps run at different potential sweep rates covering the critical potential; $1 \mathrm{~N} \mathrm{NiCl}, 0.05 \mathrm{~N} \mathrm{HCl} ; 25^{\circ} \mathrm{C}$.

upwardly, and so on. Furthermore, the anodic current peak related to the returning half-cycle occurs always at the same potential but its height increases with the number of cycles. The potential at which an abrupt current increase occurs, $E_{\text {crit }}$, decreases with temperature. Both $E_{\text {crit }}$ and the anodic current peak height, $I_{\max }$, depend on $\underline{v}$ (Table 2), but no simple relationship between these magnitudes is established. Furthermore, the influence of $\underline{v}$ on $E_{\text {crit }}$ is in the direction opposite to that expected for any relatively simple electrochemical process. This actually confirms that the $E / I$ characteristics at high anodic potential is fundamentally determined by a drastic change of the electrode surface area, as is confirmed optically and discussed further on. 


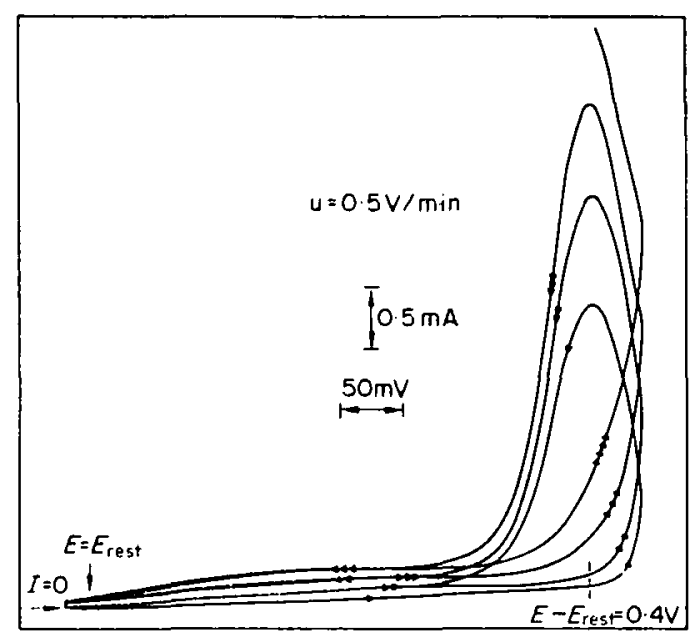

FIG. 8. Repetitive triangular potential sweeps covering the anodic potential region. The order and direction of the sweeps are indicated on the trace; $1 \mathrm{~N} \mathrm{NiCl}, 0.05 \mathrm{~N} \mathrm{HCl}$; $25^{\circ} \mathrm{C}$.

Table 2. EFfect of $\underline{v}$ ON THE POTEntiodynamic $E / I$ CuRVes

$\begin{array}{clc}v \times(\min / \mathrm{V}) & E_{\text {crit }}(\mathrm{V}) & J_{\max } \times 10^{8} / \mathrm{A} \\ 0.05 & 0.315 & 6.26 \\ 0.5 & 0.300 & 7.52\end{array}$

Surface characteristics of nickel anode

When nickel anodes are anodized at $E<E_{\text {crit }}$, they exhibit a bright uniform surface with a clear distinction of grain size and grain boundaries. But when anodic dissolution proceeds at $E>E_{\text {crit, }}$, the sample exhibits a dull surface, and localized attack at grain and subgrain boundaries is then observed, as it occurs in pitting corrosion. When this localized corrosion sets in, a rapid mechanical disintegration of the sample takes place. At $75^{\circ} \mathrm{C}$ the metal sample exhibits formation of pits.

\section{INTERPRETATION AND DISCUSSION}

In the potential region where the dissolution of $\mathrm{Ni}$ takes place, at least two definitive regions are distinguished. The first one corresponds to a dissolution process occurring uniformly and is related to a definitive relationship between $E$ and $I$. In this region, where the apparent electrode surface remains practically constant, a mechanistic interpretation of the kinetic parameters is attempted. The second region extending from $E_{\text {crit }}$ upwardly presents a continuous metal surface increase which makes the definition of the anodic current density practically impossible. Each region is considered independently.

In the anodic potential region where the smooth and uniform dissolution of $\mathrm{Ni}$ takes place, it is reasonable to assume that $\mathrm{Cl}^{-}$ions are specifically absorbed on the electrode surface since the potential of zero charge of $\mathrm{Ni} \mathrm{in} \mathrm{Cl}^{-}$ion containing solution lies between -193 and $-60 \mathrm{mV}$ (vs NHE). ${ }^{1}$ Thus, the structure of the inner layer at the metal/solution interface should mainly correspond to a $\mathrm{Ni}^{+}-\mathrm{Cl}^{-}$structure 
with an appreciable chemical free energy contribution in the adsorption process. ${ }^{6,7}$ The presence of an appreciable amount of adsorbed $\mathrm{Cl}^{-}$suggests a competitive adsorption between adsorbed $\mathrm{Cl}^{-}$ion and oxo- or hydroxosurface complexes which may determine in part either the active or passive behaviour of the metal.

At high anodic potentials a local increase and saturation of the interface with $\mathrm{NiCl}_{2}$ probably occur. The solid compound likely corresponds to an electrical conductor, as deduced from its enthalpy of formation. ${ }^{8,9} \mathrm{~A}$ rather small band gap is expected for solid $\mathrm{NiCl}_{2}$.

\section{Probable reaction path for the anodic dissolution of nickel}

Experiments previously described showed conclusively that at potentials lower than $E_{\text {crit }}$, any increase of the geometric electrode area is negligible. This is clearly concluded from Fig. 8, which shows a linear relationship between the current peak of the $n$th cycle with the current baseline of the $(n+1)$ th cycle. Therefore, there is no appreciable error on assuming that a constant surface area prevails during the uniformly active metal dissolution.

Most of the different reaction mechanisms postulated for the anodic dissolution of $\mathrm{Ni}$ implied the participation of either the $\mathrm{H}^{+}$or the $\mathrm{OH}^{-}$ion, ${ }^{1,2}$ except one which assumes a direct dissolution through the formation of $\mathrm{Ni}^{+}$species. 3,4 The latter was advanced to explain the apparent independence of the anodic dissolution current on $\mathrm{pH}$, which is partially confirmed in the present work, when the $\mathrm{Cl}^{-}$and $\mathrm{Ni}^{2+}$ ion concentrations in solution are relatively high.

The explanation of the results can be formulated in terms of the following scheme involving a consecutive reaction path without any appreciable diffusional contribution:

$$
\begin{aligned}
& \mathrm{Ni}+\mathrm{H}_{2} \mathrm{O} \underset{k_{-1}}{\stackrel{k_{1}}{\rightleftharpoons}} \mathrm{NiOH}+\mathrm{H}^{+}+e, \\
& k_{2} \\
& \mathrm{NiOH}+\mathrm{H}^{+} \underset{k_{-2}}{\stackrel{k_{2}}{\rightleftharpoons}} \mathrm{Ni}^{+}+\mathrm{H}_{2} \mathrm{O}, \\
& \mathrm{Ni}^{+} \underset{k_{-3}}{\stackrel{k_{3}}{\rightleftharpoons}} \mathrm{Ni}^{2+}+e .
\end{aligned}
$$

The rate equations for each partial step are:

$$
\begin{gathered}
i_{1}=i_{01}\left\{\exp \left[\frac{\alpha_{1} F}{R T} \eta\right]-A \exp \left[-\frac{\left(1-\alpha_{1}\right) F}{R T} \eta\right]\right\}=i_{a 1}-i_{c 1} \\
v_{2}{ }^{\prime}=v_{02}{ }^{\prime} A-v_{02}{ }^{\prime} B=v_{a 2}{ }^{\prime}-v_{c 2}{ }^{\prime} \\
i_{3}=i_{03}\left\{B \exp \left[\frac{\alpha_{3} F}{R T} \eta\right]-C\left[-\frac{\left(1-\alpha_{3}\right) F}{R T} \eta\right]\right\}=i_{a 3}-i_{c 3} .
\end{gathered}
$$


where $\eta$ is the anodic overvoltage defined as $E-E_{\mathrm{rev}}^{\mathrm{Ni}}, i_{k}, i_{0 k}, v_{k}{ }^{\prime}$ and $\alpha_{k}$ are respectively the current density, exchange current density, reaction rate and transfer coefficient assisting the reaction in the anodic direction of step $k . A, B$ and $C$ are defined as follows:

$$
\begin{aligned}
& A=\frac{C_{\mathrm{NiOH}}^{e}}{C_{\mathrm{NiOH}}^{0}} \times \frac{C_{\mathrm{H}^{+}}^{e}}{C_{\mathrm{H}^{+}}^{-}} ;
\end{aligned}
$$

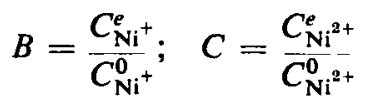

where $C$ is the concentration of species $i$ at the electrode surface $(e)$ and in the bulk of the solution ( 0$)$. Under stationary conditions:

$$
i_{1}=F v_{2}^{\prime}=i_{3}=v_{2}
$$

and the total current density, $i$, is:

$$
i=i_{1}+i_{3}=2 i_{1}=2 i_{3}=2 v_{2} .
$$

Under a steady concentration of $\mathrm{NiOH}$ and $\mathrm{Ni}^{+}$species

$$
i_{a}+v_{2 c}=i_{c}+v_{2 a}
$$

and

$$
v_{2 a}+i_{3 c}=v_{2 c}+i_{3 a} .
$$

From equations (10), (11), (4) and (5), the concentration ratios of $A$ and $B$ are respectively:

$$
A=\frac{i_{01} \exp \left[\begin{array}{l}
\alpha_{1} F \\
R T
\end{array}\right]+v_{02}{ }^{\prime} B}{i_{01} \exp \left[-\frac{\left(1-\alpha_{1}\right) F}{R T} \eta\right]+v_{02}^{\prime}}
$$

and

$$
B=\frac{v_{02}{ }^{\prime} A+i_{03} C \exp \left[-\frac{\left(1-\alpha_{3}\right) F}{R T} \eta\right]}{v_{02}{ }^{\prime}+i_{03} \exp \left[\frac{\alpha_{3} F}{R T} \eta\right]}
$$

The stationary current, according to equation (9) is twice the $i_{3}$ value. Therefore, taking into account equations (9,4-6), after replacing $A$ and $B$ by their expressions (12) and (13), respectively, one obtains: 


$$
i=2 i_{00}\left\{\begin{array}{r}
\left\{\frac{i_{01}}{i_{03}} \exp \left[\frac{\left(\alpha_{1}+\alpha_{3}\right) F}{R T} \eta\right]+C \exp \left[-\frac{\left(1-2 \alpha_{8}\right) F}{R T} \eta\right]\right\}-\left\{\frac{i_{01}}{i_{03}} C \exp \right. \\
{\left[\frac{\left(2-\alpha_{1}-\alpha_{3}\right) F}{R T} \eta\right]+C \exp \left[-\frac{\left(1-2 \alpha_{3}\right) F}{R T} \eta\right]}
\end{array}\right\}
$$

This is the $E / I$ equation for anodic and cathodic processes involved at the Ni electrode in $\mathrm{Cl}^{-}$containing solutions under quasi-stationary conditions, deduced from the postulated reaction mechanism.

Under an anodic polarization implying $i_{a} \gg i_{c}$, equation (14) becomes

$$
i_{a}=\frac{2 i_{03}\left\{\frac{i_{01}}{i_{03}} \exp \left[\frac{\left(\alpha_{1}+\alpha_{3}\right) F}{R T} \eta\right]+C \exp \left[-\frac{\left(1-2 \alpha_{3}\right) F}{R T} \eta\right]\right\}}{\frac{i_{01}}{i_{03}} \exp \left[-\frac{\left(1-\alpha_{1}\right) F}{R T} \eta\right]+\frac{i_{01}}{v_{02}} \exp \left[-\frac{\left(1-\alpha_{1}-\alpha_{9}\right) F}{R T} \eta\right]+\exp \left[\frac{\alpha_{3} F}{R T} \eta\right]} .
$$

To evaluate the potential regions where equation (15) approaches a Tafel line, the following substitutions can be made:

$$
\frac{i_{01}}{i_{03}}=10^{x} ; \quad \frac{v_{02}}{i_{03}}=10^{y} ; \quad C=1 .
$$

Equation (16) then becomes:

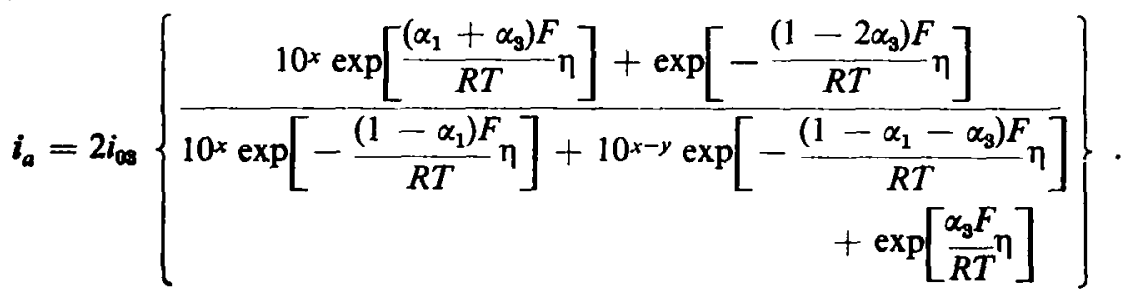

Since the slope of the $E / \log i$ plot increases with potential, in principle, the exponents should be in the order $x>y \geq 0$. After assuming that the error of the rate parameters is within 10 per cent, a figure which is easily justified in this type of measurement, equation (17) can be used to determine the potential range of possible Tafel relationships. This can be done by neglecting each of the terms in the numerator in turn and assuming a different weight for the three terms appearing in the denominator. The different possibilities are assembled in Table 3 where the conditions prevailing for the overpotential are also included.

According to the rate equations indicated in Table 3, the reaction may come 
TABle 3. Conditions for Limiting ANOdic TAFel sLopes Derived from EQUATION (17)

$$
\begin{aligned}
\mathrm{I} & =10^{x} \exp \left[-\frac{\left(1-\alpha_{1}\right) F \eta}{R T}\right] \\
\mathrm{II} & =10^{x-y} \exp \left[-\frac{\left(1-\alpha_{1}-\alpha_{2}\right) F \eta}{R T}\right] \\
\mathrm{III} & =\exp \left[\frac{a_{3} F \eta}{R T}\right]
\end{aligned}
$$

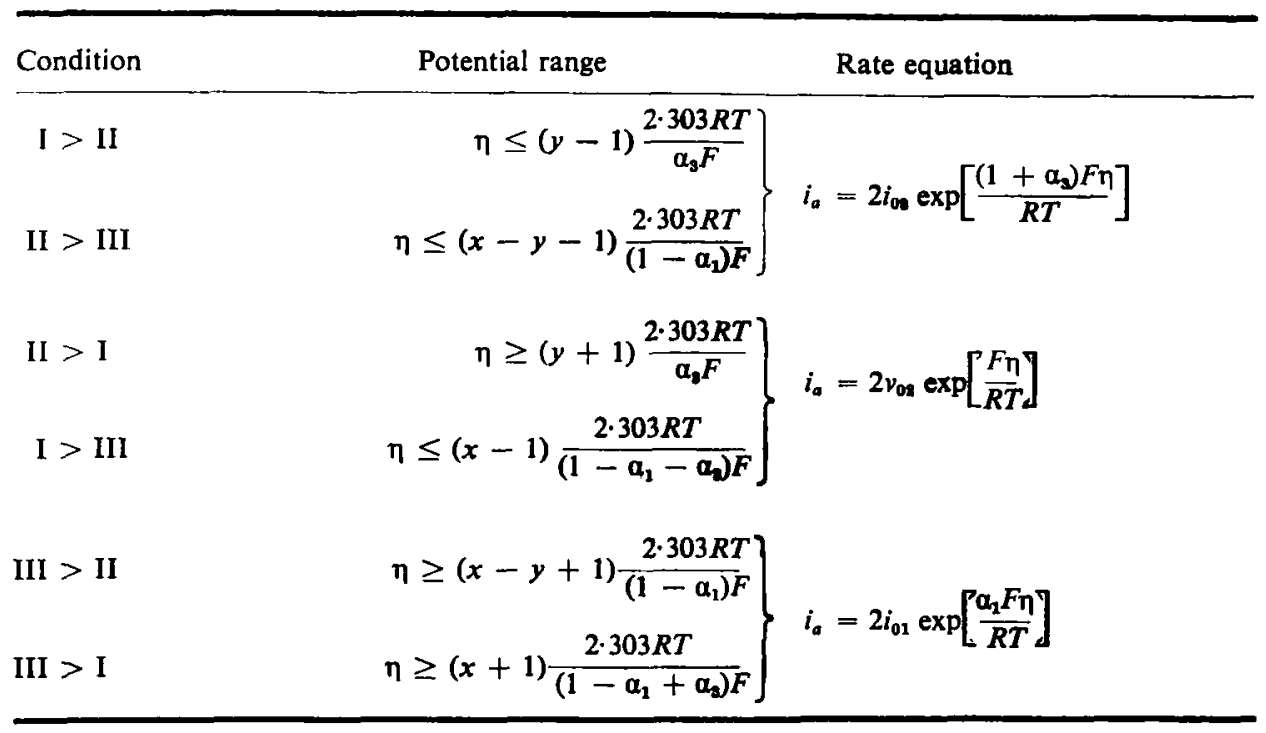

under a different control as the anodic overvoltage increases. With low overvoltage step (3) is rate-determining, at intermediate overvoltage the chemical reaction (2) is rate-determining, and at high overvoltage step (1) becomes rate-determining. Consequently the anodic Tafel slope, under stationary conditions, may change continuously from $2 \cdot 303(2 R T / 3 F)$ up to $2 \cdot 303(2 R T / F)$. These two values are approached asymptotically at low and high anodic overpotential, respectively. The intermediate slope $2 \cdot 303(R T / F)$ is often referred to by different authors as the anodic Tafel slope characterizing the anodic dissolution of $\mathrm{Ni}$ in aqueous acid solutions. ${ }^{2}$

The general rate equation for the anodic dissolution predicts therefore a curve $E / \log I$ plot instead of a linear relationship. Linear Tafel lines can be approximated but only within relatively narrow potential regions.

From the preceding analysis, at $25^{\circ} \mathrm{C}$, and assuming $\alpha_{k}=0.5$, it can be concluded (i) a Tafel slope of $0.040 \mathrm{~V}$ implies $x>y+1>2$; (ii) a Tafel slope equal to $0.060 \mathrm{~V}$ is found if $x \geq 2 y+4$ and (iii) a curve approaching the Tafel slope of $0.120 \mathrm{~V}$ results when $\eta \geq 0 \cdot 240 \mathrm{~V}$. The third possibility exists for any of the following set of exponents; $x=2, y=1 ; x=1, y=0$ and $x=0, y=-1$. Case (iii) corresponds to a continuous $E / \log I$ curve approaching the slope 2.303(2RT/F).

The anodic current density equations derived from the reaction path just discussed, with either step (1), (2) or (3) as rate-determining, are independent both on $\mathrm{pH}$ and 
$\mathrm{Ni}^{2+}$ ion concentration. This is immediately seen if the rate equations are expressed in terms of $E$ instead of $\eta$.

The electrodeposition of $\mathrm{Ni}^{2+}$ ion involves a cathodic Tafel slope equal to $2 R T / F$ which is also explained in terms of the same reaction path. According to equation (14), at any cathodic overpotential where $x>y$, step (3) is rate-determining. Then, the rate equation of the cathodic process is:

$$
i_{c}=2 i_{03} \exp \left[-\frac{\left(1-\alpha_{3}\right) F}{R T} \eta\right]=k_{c \mathrm{Ni}} C_{\mathrm{Ni}^{2}} \exp \left[-\frac{\left(1-\alpha_{3}\right) F}{R T} E\right] .
$$

The rate equation is independent of $\mathrm{pH}$ and implies a first order dependence on $\mathrm{Ni}^{2+}$ ion concentration. By equating the rate of the anodic process and the rate of the cathodic process at $E=E_{\mathrm{rev}}$, the Nernst equation for the Ni electrode is immediately obtained.

The $\mathrm{H}^{+}$ion discharge on $\mathrm{Ni}$ in acid solutions is a relatively complex process. ${ }^{10}$ Altogether there is a good evidence for a first order rate process with respect to $\mathrm{H}^{+}$ion, involving a Tafel slope close to $2 \cdot 303(2 R T / F)$. Hence, at $E=E_{\mathrm{corr}}, i_{a}=i_{\mathrm{cH}}=$ $i_{\text {corr }}$ and

$$
i_{\text {corr }}=k_{a \mathrm{Ni}} \exp \left[\frac{\left(1+\alpha_{3}\right) F}{R T} E_{\text {corr }}\right]=k_{c \mathrm{H}} C_{\mathrm{H}^{+}} \exp \left[-\frac{F}{2 R T} E_{\text {corr }}\right]
$$

where the $k$ 's involve $n F$, the rate constants and the corresponding equilibrium concentrations of each step. At a constant $\mathrm{Ni}^{2+}$ ion concentration, equation (19) predicts a linear $E_{\text {corr }} / \mathrm{pH}$ relationship, with a slope equal to $-2 \cdot 303(R T / 2 F)$. A departure from equation (19) is not unlikely at $\mathrm{pH} \leq 0$, because the condition of a constant potential at the outer Helmholtz plane is probably no longer held.

The postulated reaction mechanism explains the kinetic features of the Ni electrode in $\mathrm{Cl}^{-}$ion containing solutions. The present discussion shows the actual difficulty of deriving a single anodic Tafel slope from stationary $E / I$ curves covering the whole potential range of the active dissolution of $\mathrm{Ni}$ in those media.

This mechanism involves an anodic dissolution process which is $\mathrm{pH}$ independent in spite of the participation of either $\mathrm{H}_{2} \mathrm{O}, \mathrm{OH}^{-}$or $\mathrm{H}^{+}$ion species in the reaction. The only formal difference between this reaction mechanism and the mechanism already known for metals of the iron group is caused by the stabilization of $\mathrm{Ni}^{+}$ species in the acid solutions as well as the $\mathrm{Cl}^{-}$adsorption which prevents any appreciable passivation of the metal either by $\mathrm{H}_{2} \mathrm{O}$ or $\mathrm{OH}^{-}$ion.

\section{The region of non-uniform corrosion}

The potentiodynamic $E / I$ curves, at high anodic potentials, exhibit an anodic current peak which is relatively symmetrical with respect to $E_{\text {crit }}$. Furthermore, the slope of the $E / I$ curve at the end of the anodic scan is practically equal, in absolute terms, to the slope at the beginning of the cathodic scan. This indicates that the $\mathrm{Ni}$ electrode area changes at the same rate when the potential is swept continuously either from $E_{\text {crit }}$ to $E>E_{\text {crit }}$ or reversing.

At $E>E_{\text {crit }}$ the non-uniform corrosion is due to unstable currents. A $\log i / \log t$ plot at $t>2 \mathrm{~min}$ (Fig. 9) approaches a straight line according to an Engell-Stolica 


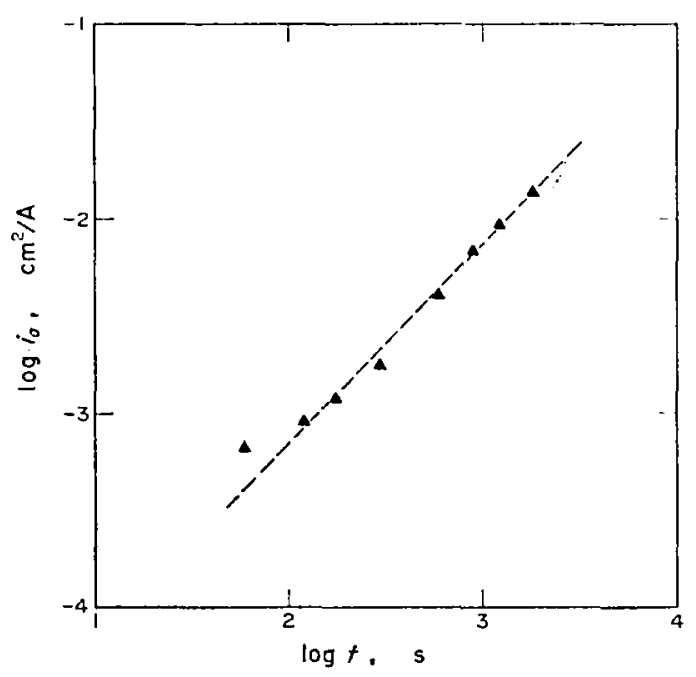

FIG. 9. Time dependence of the anodic current density at $E=0.010 \mathrm{~V} ; 1 \mathrm{~N} \mathrm{NiCl}_{2}$, $0.05 \mathrm{~N} \mathrm{HCl} ; 75^{\circ} \mathrm{C}$.

equation. ${ }^{11}$ At $t>2$ min the slope of the straight line is one. These results agree with existing data on pitting corrosion of $\mathrm{Ni}^{12-16}$ The steady increase of the exponent in the Engell-Stolica equation, from $b \rightarrow 0$, when $t \rightarrow 0$, to $b \rightarrow 1$, when $t \rightarrow \infty$, has been interpreted as a pit geometry change occurring during the early stages of pitting corrosion of $\mathrm{Ni}$, until a stationary situation mainly involving a (111) crystal orientation is attained. ${ }^{17}$

Acknowledgement-This work is part of the research program of the Electrochemistry Division of INIFTA, sponsored by the Universidad Nacional de La Plata, the Consejo Nacional de Investigaciones Cientificas y Técnicas and the Comisión de Investigaciones Científicas de la Pcia. de Buenos Aires. J. R. V. thanks the Comisión de Investigaciones Cientificas de la Pcia. de Buenos Aires for the fellowship granted (1972-73).

\section{REFERENCES}

1. A. J. Arvía and D. Posadas, in: The Electrochemistry of the Elements, Vol. III, p. 212 (Ed., A. J. BARD). M. Dekker, New York (1975).

2. I. EPELBoim and R. WiART, J. electrochem. Soc. 118, 1577 (1971).

3. F. OVARI and A. L. Rotinyan, Elektrokhimiya 6, 528 (1970).

4. A. T. Vagramyan, M. A. Zhamagortsyan, L. A. Uvarov and A. A. Yavich, Elektrokhimiya 6, 755 (1970).

5. G. Paus, A. J. Calandra and A. J. Arvía, Anal. Soc. Cient. Arg. 192, 35 (1971).

6. Y. M. KolotYrkin, Z. Elektrochem. 62, 664 (1958).

7. H. J. RätZer-Scheibe and H. G. Feller, Corros. Sci. 13, 11 (1973).

8. A. K. VIJH, Electrochemistry of Solid Materials: The Application of Solid State Science to Electrochemical Phenomena. M. Dekker, New York (1972).

9. Handbook of Chemistry and Physics (Ed., R. C. WEAST) Section D. The Chemical Rubber Co., 50th Ed. Ohio (1970).

10. A. J. Arvia, R. C. V. Piatti and J. J. PodestA, Anal. Asoc. Quim. Arg. 57, 1 (1969).

11. H. J. Engell and N. D. StoliCA, Z. Physik. Chem. N.F. 20, 113 (1959).

12. Z. SzKLarSKa-SmialowsKa, Corros. Sci. 11, 209 (1971); Werkstoffe Korr. 22, 780 (1971).

13. Z. SzKLARSKa-SmialowsKa, Corros. Sci. 12, 527 (1972).

14. M. Datta and D. Landolt, Corros. Sci. 13, 187 (1973).

15. G. W. Marshall and M. T. Jones, Corros. Sci. 14, 15 (1974).

16. M. ZAMIN and M. B. Ives, Corrosion 29, 319 (1973).

17. J. Toušex, Coll. Czechoslov. Chem. Comm. 37, 1454 (1972). 